Gut and Liver, Vol. 12, No. 5, September 2018, pp. 562-570

\title{
Patient Response to Endoscopic Therapy for Gastroesophageal Varices Based on Endoscopic Ultrasound Findings
}

\author{
Yujen Tseng ${ }^{1}$, Lili Ma ${ }^{2}$, Tiancheng Luo ${ }^{1}$, Xiaoqing Zeng ${ }^{1}$, Feng $\mathrm{Li}^{1}$, $\mathrm{Na} \mathrm{Li}^{1}$, Yichao Wei ${ }^{1}$, and Shiyao Chen ${ }^{1,2,3}$ \\ Departments of ${ }^{1}$ Gastroenterology, ${ }^{2}$ Endoscopy Center, and ${ }^{3}$ Evidence-Based Medicine Center, Zhongshan Hospital, Fudan University, Shanghai, \\ China
}

Background/Aims: Gastroesophageal variceal hemorrhage is a common complication of portal hypertension. Endoscopic therapy is currently recommended for preventing gastroesophageal variceal rebleed. However, the rate of variceal rebleed and its associated mortality remain concerning. This study is aimed at differentiating patient response to endoscopic therapy based on endoscopic ultrasound (EUS) findings. Methods: One-hundred seventy patients previously treated with repeat endoscopic therapy for secondary prophylaxis were enrolled and classified into two groups based on treatment response. Prior to consolidation therapy, all patients received an EUS examination to observe for extraluminal phenomena. All available follow-up endoscopic examination records were retrieved to validate study results. Results: Of the 170 subjects, 106 were poor responders, while 64 were good responders. The presence of para-gastric, gastric perforating, and esophageal perforating veins was associated with poor patient response $(p<0.001)$. The odds ratio for para-gastric veins was 5.374. Follow-up endoscopic findings for poor responders with incomplete variceal obliteration was closely correlated with the presence of para-gastric veins $(p=0.002)$. Conclusions: The presence of para-gastric veins is a characteristic of poor response to endoscopic therapy for treating gastroesophageal varices. Early identification of this subgroup necessitates a change in course of treatment to improve overall patient outcome. (Gut Liver 2018;12:562570)

Key Words: Esophageal and gastric varices; Endosonography; Cyanoacrylates; Risk assessment

\section{INTRODUCTION}

Portal hypertension is a progressive complication often secondary to cirrhosis. ${ }^{1}$ Common clinical presentations of portal hypertension include ascites, hepatic encephalopathy, and gastroesophageal varices. Among which, variceal hemorrhage is considered the most lethal complication, with a high mortality rate. ${ }^{2}$ Approximately 50\% of patients develop gastroesophageal varices during the course of the disease. ${ }^{1}$ Despite aggressive resuscitation, the risk of variceal rebleed after an index episode of variceal hemorrhage ranges from 50\% to 60\% within the first year with an associated mortality rate of 33\%. ${ }^{1,-5}$ According to current consensus, the first line recommended therapy is endoscopic intervention, including endoscopic band ligation (EBL) for esophageal varices, and cyanoacrylate (tissue adhesive) injection for gastric varices. ${ }^{6,7}$ Cyanoacrylate injection for the management of gastric varices can achieve an effective hemostasis in over $90 \%$ of patients. ${ }^{89}$ However, even with appropriate secondary prophylactic therapy the rate of gastroesophageal variceal rebleed remains at a concerning $42 \%$ to $43 \% .^{10-12}$ On the other hand, repeated endoscopy sessions are often necessary to achieve complete variceal obliteration, with an average of 2 to 3 sessions. Periodic endoscopy follow-ups are also mandatory for long-term disease management. ${ }^{13-16}$ Although several studies have established the benefits of transjugular intrahepatic portosystemic shunt (TIPS) application in high-risk patients, ${ }^{17,18}$ there is unfortunately a lack of uniform consensus for risk stratification. To date, few studies have focused on evaluating patient response to endotherapy sessions, despite its high evidential strength as recommended therapy for patients with gastroesophageal varices.

Endoscopic ultrasound (EUS) is a combination of endoscopic

Correspondence to: Shiyao Chen

Departments of Gastroenterology, Endoscopy Center, Evidence-Based Medicine Center, Zhongshan Hospital, Fudan University, 180 Fenglin Road, Shanghai 0086200032, China

Tel: +86-21-64041990, Fax: +86-21-64432583, E-mail: chen.shiyao@zs-hospital.sh.cn

Received on October 9, 2017. Revised on December 11, 2017. Accepted on December 21, 2017. Published online April 27, 2018

pISSN 1976-2283 eISSN 2005-1212 https://doi.org/10.5009/gnl17471

Yujen Tseng and Lili Ma contributed equally to this work as first authors.

(a) This is an Open Access article distributed under the terms of the Creative Commons Attribution Non-Commercial License (http://creativecommons.org/licenses/by-nc/4.0) which permits unrestricted non-commercial use, distribution, and reproduction in any medium, provided the original work is properly cited. 
imaging and ultrasonic capabilities, which offers a comprehensive evaluation of the portal systemic collateral circulation. EUS along with Color-Doppler function can further provide valuable hemodynamic information. ${ }^{19}$ EUS application allows for the clear visualization of both gastroesophageal varices and other venous collaterals in patients with portal hypertension. ${ }^{20}$ Several studies have investigated the correlation between collateral circulation, a result of increased portal pressure, and the recurrence of gastroesophageal varices. ${ }^{21-24}$ Currently, no reliable predictor is available to stratify the efficacy of secondary prophylactic endoscopic treatment, especially in patients with repeated endoscopy session. The purpose of this research is to investigate different extraluminal EUS phenomenon in attempt to differentiate patient response to endoscopic therapy for gastroesophageal varices. Early identification of poor responders may prompt consideration of other treatment modalities including TIPS, balloon-occluded retrograde transvenous obliteration (BRT0), splenectomy and devascularization, or partial splenic embolization (PSE). ${ }^{25}$

\section{MATERIALS AND METHODS}

The study was conducted in a single tertiary medical center from August 2015 to July 2016. Patients with a confirmed diagnosis of gastroesophageal varices secondary to portal hypertension were admitted to our hospital for secondary prophylactic treatment evaluation or endoscopic therapy for acute variceal hemorrhage. Inclusion criteria were as follows: (1) Patients over 18 years of age who received two or more endoscopic sessions, but naïve to other forms of treatment, including oral medication (non-selective beta blockers), interventional radiology (TIPS or BRT0), or surgical therapy (splenectomy and devascularization); (2) Past history of gastroesophageal variceal hemorrhage confirmed by an endoscopic examination. Exclusion criteria included: Patients who did not receive, or only received one endotherapy session for the treatment of gastroesophageal varices (Fig. 1).

Patients were divided into two group according to their response to endoscopic therapy. Poor responders were patients who experienced variceal rebleed, evident by melena or hematemesis, prior to admission. A subsequent endoscopic examination revealing the presence of gastroesophageal varices classified as grade 3 (F3 or diameter $>5 \mathrm{~mm}$ ) or had obvious red wale marks necessitating repeat endoscopic therapy were also characteristics of poor responders. The size of the varix and presence of red wale marks are independent indicators of poor response. In comparison, good responders were those with complete variceal obliteration or small varices $(<5 \mathrm{~mm})$ without red wale marks. ${ }^{26,27}$ A thorough review of each subject's patient history upon admission was conducted.

All study subjects signed an informed consent acknowledging the purpose and risks associated with the endoscopic examina- tion and treatment. This study was approved by the Ethics Committee of Zhongshan Hospital Fudan University (No. B2015135R). Procedures were commenced after an overnight fast. First, a routine endoscopic examination was performed to assess the extent and characteristics of gastroesophageal varices. Findings were classified according to Sarin's classification. Then, an endoscopic ultrasound (EUS) examination (Olympus CV260, Olympus EUS-MEI, or Aloka prosound $\alpha 5$ ) was performed to assess for extraluminal phenomena, including para-gastric veins (Fig. 2), gastric perforating veins, and esophageal perforating veins. Para-gastric vein (PGV) is defined as a group of rather large vessels distal to the gastric wall, ${ }^{27}$ which was further classified into type 1 and type $2 \mathrm{PGV}$, wherein type 1 has no evident communication with other collaterals, while type 2 is a sub-branch of the splenic vein (Fig. 3). ${ }^{28}$ EUS examination was performed by placing the probe against the fundic wall to identify the splenic vein, then slowly moved along the fundus towards the cardia. All extraluminal phenomenon were recorded.

After thorough observation, endoscopic therapy was performed as for consolidation purposes for secondary prophylaxis. Depending on the different degree and presentation of gastroesophageal varices, each patient received appropriate individualized therapy. EUS and endoscopic therapy were achieved in one session. Gastric varices were uniformly treated with cyanoacrylate injection, while either endoscopic band ligation (EBL) or endoscopic injection sclerotherapy (EIS) was performed for esophageal varices. Cyanoacrylate injection abided by the sandwich technique, which included an initial injection of lauromacrogol (Tianyu Pharmaceutical, Zhejiang, China), followed by N-butyl-cyanoacrylate (Beijing Suncon Medical Adhesive Co. Ltd, Beijing, China), then again by lauromacrogol. ${ }^{15}$ The volume of lauromacrogol and cyanoacrylate used directly correlated with the size of the varix. Lauromacrogrol volume ranged

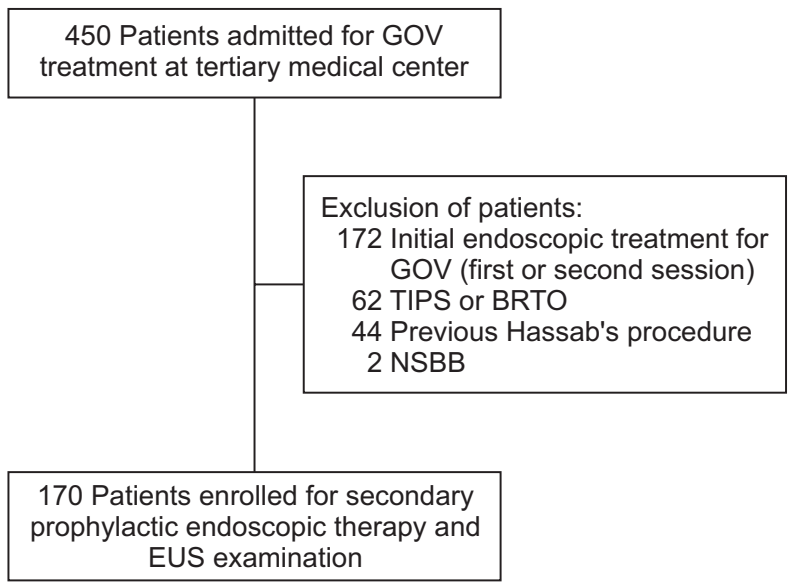

Fig. 1. Study flowchart based on inclusion and exclusion criteria. GOV, gastroesophageal varices; TIPS, transjugular intrahepatic portosystemic shunt; BRTO, balloon-occluded retrograde transvenous obliteration; NSBB, non-selective beta blockers; EUS, endoscopic ultrasound. 

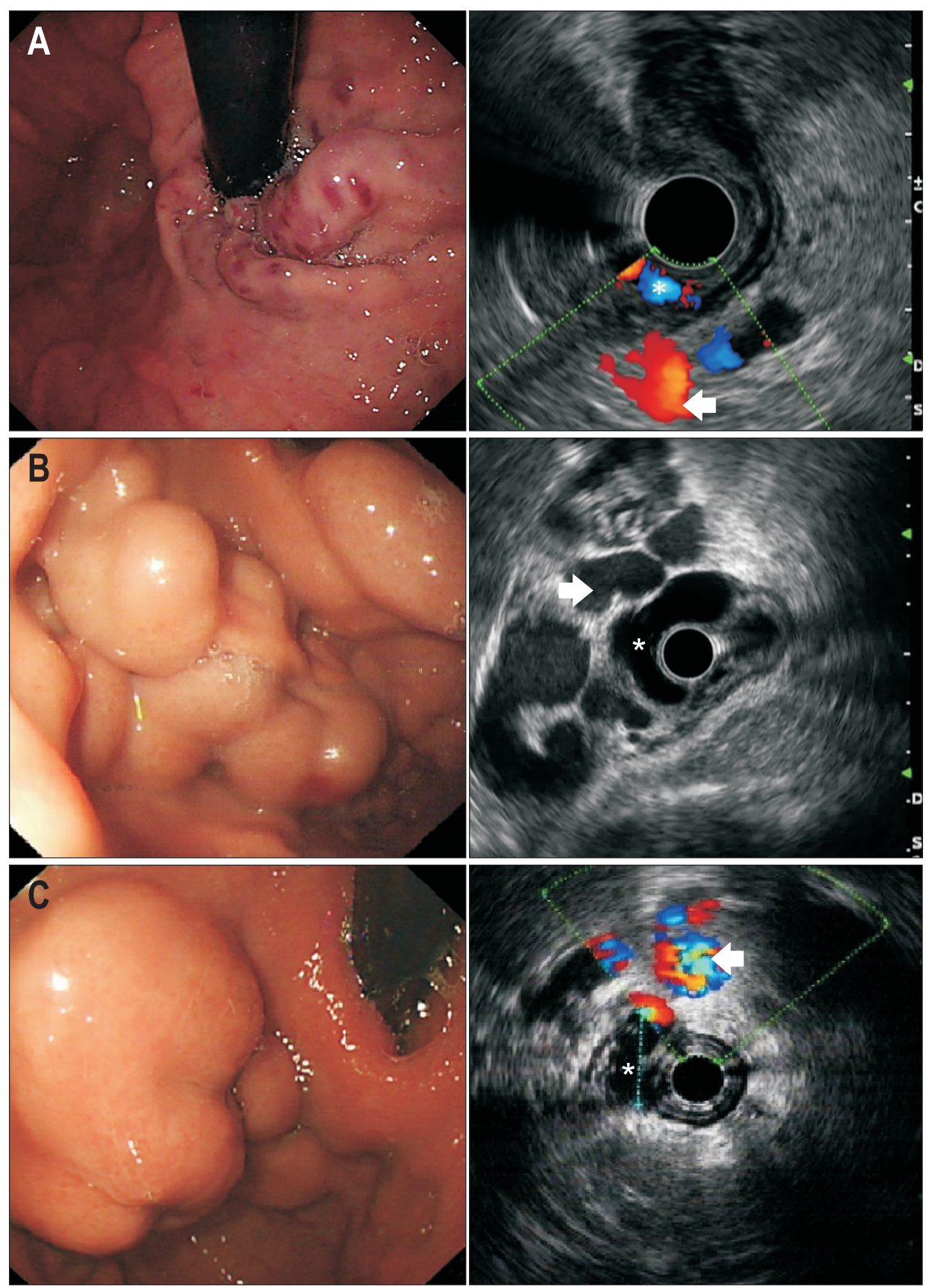

Fig. 2. (A) GOV type 1; (B) GOV type 2; (C) IGV type 1. Compilation of endoscopic presentations of GOV and their corresponding endoscopic ultrasound prior to cyanoacrylate injection (extraluminal para-gastric vein is marked by an arrow).

GOV, gastroesophageal varices. *The intraluminal varix is identified.

from 2 to $10 \mathrm{~mL}$, while that of cyanoacrylate ranged from 0.5 to $2 \mathrm{~mL}$. Gastric varices obturation was attempted in one session, prompting multiple site injection when deemed necessary. The needle sheath was held at the puncture site until the varix solidified, turned pale, and became less mobile. All endoscopic diagnosis and treatment procedures were performed by one of two experienced endoscopists (L.M. and S.C.), each with over 20 years of experience. Patients who did not require repeat endoscopic therapy were considered as good responders. After initial post-procedural stabilization, patients were discharged and followed-up closely at a designated out-patient service clinic.

Patients with available follow-up endoscopy examination were further analyzed to validate study results. Based on endoscopy findings, patients were divided into variceal obliterated group and non-obliterated group. The relationship between variceal obliteration and presence of para-gastric veins were analyzed.

Statistical analyses were performed via SPSS version 22.0 (IBM Corp., Armonk, NY, USA). Categorical variables were expressed as frequency (\%), while continuous variables were expressed as mean \pm standard deviation. Comparison between categorical variables were achieved through the chi-square test or Pearson's correlation, while continuous variables were compared using the independent Student t-test. All statistically 

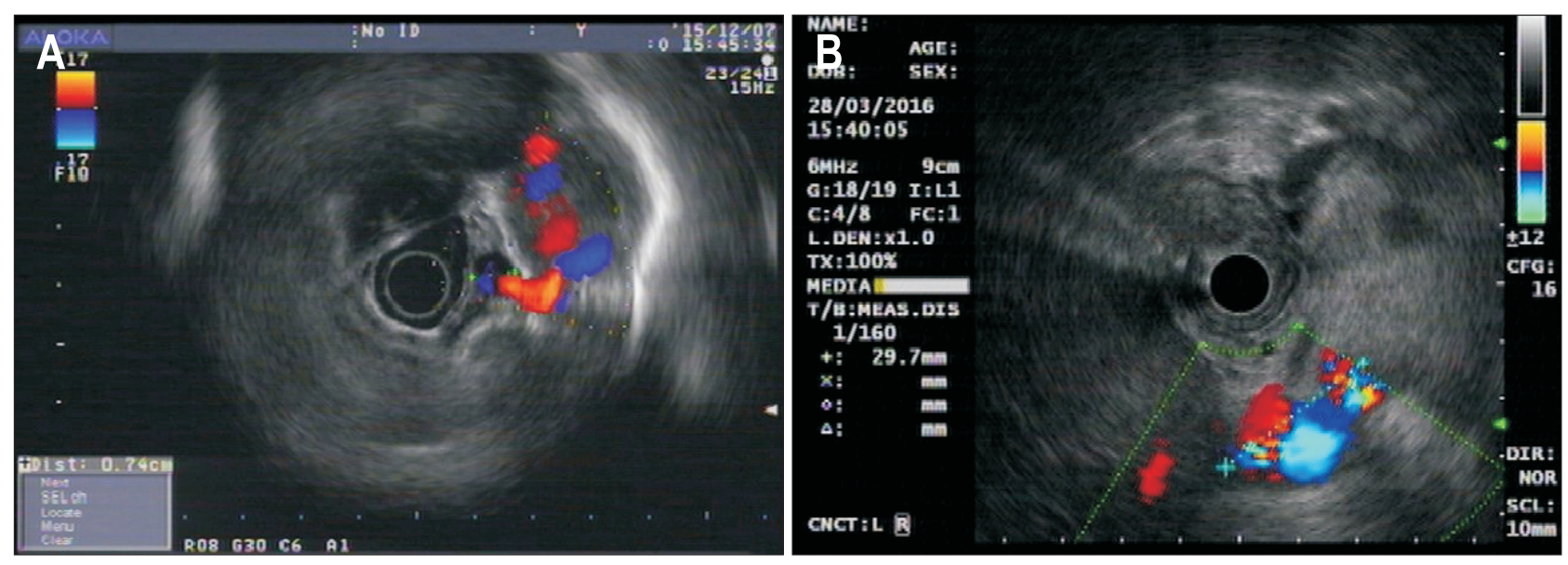

Fig. 3. Classification of type 1 (A) and type 2 (B) para-gastric veins (PGVs). Type 1 PGV showed no evident correlation with other collaterals, while type 2 was a splenic vein sub-branch.

significant variables were further assessed through a binary logistic regression. All statistical analyses were two-sided with a p-value $<0.05$ considered statistically significant.

\section{RESULTS}

From August 2015 to July 2016, 450 patients were admitted to Zhongshan Hospital for gastroesophageal varices secondary to portal hypertension. Two hundred and eighty subjects were excluded based on the priori established exclusion criteria, including those with previous history of splenectomy and devascularization, use of $\beta$-blockers or patients who received less than two sessions of endoscopic therapy. One hundred and seventy subjects fulfilled the inclusion criteria for repeated secondary prophylaxis treatment of gastroesophageal varices. Characteristics of included subjects are summarized in Table 1.

One hundred fourteen patients (67.1\%) were male, 56 (32.9\%) were female, with an average age of 58.62 \pm 9.61 years old, ranging from 34 to 81 years old. The average Child-Pugh score was $6.06 \pm 1.06$, with most patients classified as Child-Pugh class A and class B (70.6\% and 28.8\%, respectively). The most common etiology for portal hypertension is cirrhosis secondary to viral hepatitis, accounting for $58.2 \%$ of the study population (54.7\% hepatitis B virus [HBV] and 3.5\% hepatitis C virus). Other etiologies include alcoholic cirrhosis (8.2\%), primary biliary cirrhosis (7.6\%), autoimmune hepatitis (5.3\%), schistosomiasis cirrhosis (3.5\%), cryptogenic (12.4\%) and mixed etiologies (0.6\%). Observed concurrent conditions included portal venous thrombosis (PVT), hepatic cellular carcinoma (HCC) and ascites, as evident on imaging examinations. Thirty-six patients had concurrent PVT (21.2\%), 15 patients had HCC (8.8\%), and 66 patients had ascites (38.8\%). The average time from the last endoscopic therapy session to study inclusion was $36.27 \pm 18.40$ weeks.

Gastroesophageal varices were classified according to the Japanese Society of Portal Hypertension and Sarin's classifica- tion. $^{27,29}$ Gastroesophageal varices type 2 remains the most common form of concurrent esophageal and gastric varices (24.7\%), while esophageal varices were observed in 68 patients (40.0\%). Under EUS observations, 75 patients (44.1\%) presented with PGV, with PGV type 2 as the predominant form. Gastric perforating vein was observed in 82 patients $(48.2 \%)$, while esophageal perforating vein was observed in 93 (54.7\%). A total of 100 patients (58.8\%) received endoscopic therapy to further consolidate the initial prophylactic measure, including 17 (10.0\%) cases of esophageal banding ligation (EBL), 21 (12.4\%) cases of endoscopic injection sclerotherapy (EIS), 19 (11.2\%) cases of cyanoacrylate injection, 24 (14.1\%) cases of EBL+canoacrylate and 19 (11.2\%) cases of EIS+cyanoacrylate. Regardless of classification, all gastric varices were uniformly treated with cyanoacrylate injection. ${ }^{29,30}$ The average number of endoscopic therapy sessions was $3.7 \pm 1.66$.

Patients were divided into two groups based on their response to repeat endoscopic therapy, which is defined by evident variceal rebleed prior to hospital admission or subsequent endoscopic findings. The baseline characteristics between two groups were compared (Table 2). Six patients in the poor responder group failed to follow through with recommended therapy due to personal, financial concerns, or incompliance.

The baseline characteristics of the two patient groups were compared (Table 2). The presence of para-gastric veins, gastric perforating veins, and esophageal perforating veins reached a statistical significance of $\mathrm{p}<0.001$. While, age, hemoglobin, and prothrombin time (second) had a p-value of 0.018, 0.024, and 0.050 respectively.

A binary logistic regression was conducted to evaluate the significant variables from the univariate analysis. Results are shown in Table 3. The presence of para-gastric vein has the highest odds ratio (OR) of 5.374 (95\% CI [confidence interval], 1.013 to 28.475), followed by the presence of gastric perforating vein, with an OR of 2.908 (95\% CI, 1.174 to 7.201). 
Table 1. Baseline Characteristics of the Global Population $(n=170)$

\begin{tabular}{|c|c|}
\hline Parameters & Global population $(\mathrm{n}=170)$ \\
\hline \multicolumn{2}{|l|}{ General characteristics } \\
\hline \multicolumn{2}{|l|}{ Sex } \\
\hline Male & $114(67.1)$ \\
\hline Female & $56(32.9)$ \\
\hline Age, yr & $58.62 \pm 9.61$ \\
\hline Child-Pugh score & $6.06 \pm 1.06$ \\
\hline \multicolumn{2}{|l|}{ Child-Pugh classification } \\
\hline Class A & $120(70.6)$ \\
\hline Class B & $49(28.8)$ \\
\hline Class C & $1(0.6)$ \\
\hline \multicolumn{2}{|l|}{ Etiology of portal hypertension } \\
\hline HBV & $93(54.7)$ \\
\hline $\mathrm{HCV}$ & $6(3.5)$ \\
\hline Alcohol & $14(8.2)$ \\
\hline PBC & $13(7.7)$ \\
\hline $\mathrm{AIH}$ & $9(5.3)$ \\
\hline Schistosomiasis & $6(3.5)$ \\
\hline Cryptogenic & $21(12.4)$ \\
\hline Mixed & $7(4.1)$ \\
\hline Others & $1(0.6)$ \\
\hline \multicolumn{2}{|l|}{ Laboratory parameters } \\
\hline Total bilirubin, $\mu \mathrm{mol} / \mathrm{L}$ & $19.74 \pm 16.21$ \\
\hline Conjugated bilirubin, $\mu \mathrm{mol} / \mathrm{L}$ & $9.10 \pm 13.73$ \\
\hline Albumin, g/L & $38.42 \pm 4.66$ \\
\hline ALT, U/L & $28.12 \pm 18.70$ \\
\hline AST, U/L & $34.35 \pm 21.45$ \\
\hline Hemoglobin, g/L & $110.71 \pm 25.16$ \\
\hline Platelet, $\times 10^{9} / \mathrm{L}$ & $62.67 \pm 29.21$ \\
\hline Prothrombin time, s & $13.74 \pm 1.30$ \\
\hline Serum creatinine, $\mu \mathrm{mol} / \mathrm{L}$ & $74.62 \pm 22.00$ \\
\hline No. of endotherapy sessions & $3.7 \pm 1.66$ \\
\hline \multicolumn{2}{|l|}{ Variceal recurrence } \\
\hline Absent & $64(37.6)$ \\
\hline Present & $106(62.4)$ \\
\hline \multicolumn{2}{|l|}{ Endoscopic findings } \\
\hline \multicolumn{2}{|l|}{ Esophageal varices } \\
\hline None & $49(28.8)$ \\
\hline Mild & 37 (21.8) \\
\hline Moderate & $13(7.6)$ \\
\hline Severe & $71(41.8)$ \\
\hline No varices & $38(22.4)$ \\
\hline Isolated EV & $68(40.0)$ \\
\hline \multicolumn{2}{|l|}{ Sarin's classification } \\
\hline GOV type 1 & $11(6.5)$ \\
\hline GOV type 2 & $42(24.7)$ \\
\hline IGV type 1 & $11(6.5)$ \\
\hline IGV type 2 & 0 \\
\hline
\end{tabular}

Table 1. Continued

\begin{tabular}{|c|c|}
\hline Parameters & Global population $(n=170)$ \\
\hline \multicolumn{2}{|l|}{ Concurrent conditions } \\
\hline \multicolumn{2}{|l|}{ Portal venous thrombosis } \\
\hline Absent & $134(78.8)$ \\
\hline Present & $36(21.2)$ \\
\hline \multicolumn{2}{|l|}{ Hepatocellular carcinoma } \\
\hline Absent & $155(91.2)$ \\
\hline Present & $15(8.8)$ \\
\hline \multicolumn{2}{|l|}{ Ascites } \\
\hline Absent & $104(61.2)$ \\
\hline Present & $66(38.8)$ \\
\hline \multicolumn{2}{|l|}{ EUS phenomenon } \\
\hline \multicolumn{2}{|l|}{ Para-gastric veins } \\
\hline Absent & 95 (55.9) \\
\hline Present & $75(44.1)$ \\
\hline Para-gastric veins diameter, $\mathrm{cm}$ & $1.35 \pm 1.72$ \\
\hline \multicolumn{2}{|l|}{ PGV classification } \\
\hline None & $95(55.9)$ \\
\hline Type 1 & $20(11.8)$ \\
\hline Type 2 & $55(32.3)$ \\
\hline \multicolumn{2}{|l|}{ Gastric perforating vein } \\
\hline Absent & $88(51.8)$ \\
\hline Present & $82(48.2)$ \\
\hline \multicolumn{2}{|l|}{ Esophageal perforating vein } \\
\hline Absent & $77(45.3)$ \\
\hline Present & $93(54.7)$ \\
\hline \multicolumn{2}{|l|}{ Treatment received } \\
\hline None & $70(41.2)$ \\
\hline EBL & $17(10.0)$ \\
\hline EIS & $21(12.3)$ \\
\hline Cyanoacrylate & $19(11.2)$ \\
\hline EBL+cyanoacrylate & $24(14.1)$ \\
\hline EIS+cyanoacrylate & $19(11.2)$ \\
\hline Volume of cyanoacrylate used & $0.60 \pm 0.93$ \\
\hline
\end{tabular}

Data are presented as number (\%) or mean \pm SD.

$\mathrm{HBV}$, hepatitis B virus; HCV, hepatitis C virus; $\mathrm{PBC}$, primary biliary cirrhosis; AIH, autoimmune hepatitis; ALT, alanine transaminase; AST, aspartate transaminase; EV, esophageal varices; GOV, gastroesophageal varices; IGV, isolated gastric varices; EUS, endoscopic ultrasound; PGV, para-gastric vein; EBL, esophageal banding ligation; EIS, endoscopic injection sclerotherapy.

A retrospective review of the hospital database was conducted in attempt identify available follow-up endoscopy examination of all study subjects. Among the poor responders ( $n=106), 61$ patients (57.5\%) received a follow-up endoscopy examination, with an average time to follow-up of $5.92 \pm 2.45$ months (Table 4). Thirty-two patients (52.5\%) had complete variceal obliteration, while 29 (47.5\%) had remnant varices, requiring further intervention, evident by F3 varix or red wale mark. The results 
Table 2. Comparison between Poor Responders and Good Responders

\begin{tabular}{|c|c|c|c|}
\hline Parameters & $\begin{array}{c}\text { Poor } \\
\text { responders } \\
(n=106)\end{array}$ & $\begin{array}{c}\text { Good } \\
\text { responders } \\
(\mathrm{n}=64)\end{array}$ & p-value \\
\hline \multicolumn{4}{|l|}{ General characteristics } \\
\hline Sex & & & 0.757 \\
\hline Male & $72(67.9)$ & $42(65.6)$ & \\
\hline Female & $34(32.1)$ & $22(34.4)$ & \\
\hline Age, yr & $57.27 \pm 9.68$ & $60.84 \pm 9.14$ & 0.018 \\
\hline Child-Pugh score & $6.14 \pm 1.11$ & $5.92 \pm 0.97$ & 0.191 \\
\hline Child-Pugh classification & & & 0.207 \\
\hline Class A & $70(66.0)$ & $50(78.1)$ & \\
\hline Class B & $35(33.0)$ & 14 (21.9) & \\
\hline Class C & $1(1.0)$ & 0 & \\
\hline Etiology of portal hypertension & & & 0.854 \\
\hline HBV & $56(52.8)$ & $37(57.8)$ & \\
\hline $\mathrm{HCV}$ & $5(4.7)$ & $1(1.6)$ & \\
\hline Alcohol & $7(6.6)$ & $7(11.0)$ & \\
\hline PBC & $8(7.6)$ & $5(7.8)$ & \\
\hline $\mathrm{AIH}$ & $7(6.6)$ & $2(3.1)$ & \\
\hline Schistosomiasis & $4(3.8)$ & $2(3.1)$ & \\
\hline Cryptogenic & $13(12.3)$ & $8(12.5)$ & \\
\hline Mixed & $5(4.7)$ & $2(3.1)$ & \\
\hline Others & $1(0.9)$ & 0 & \\
\hline GI bleeding prior to admission & $16(15.1)$ & 0 & 0.000 \\
\hline \multicolumn{4}{|l|}{ Laboratory Parameters } \\
\hline Total bilirubin, $\mu \mathrm{mol} / \mathrm{L}$ & $20.95 \pm 19.30$ & $17.73 \pm 8.77$ & 0.209 \\
\hline Conjugated bilirubin, $\mu \mathrm{mol} / \mathrm{L}$ & $9.90 \pm 16.83$ & $7.75 \pm 5.48$ & 0.323 \\
\hline Albumin, $\mathrm{g} / \mathrm{L}$ & $38.30 \pm 4.73$ & $38.61 \pm 4.57$ & 0.678 \\
\hline ALT, U/L & $27.21 \pm 20.64$ & $29.64 \pm 14.98$ & 0.413 \\
\hline AST, U/L & $34.12 \pm 24.30$ & $34.73 \pm 15.80$ & 0.858 \\
\hline Hemoglobin, g/L & $107.33 \pm 26.02$ & $116.30 \pm 22.77$ & 0.024 \\
\hline Platelet, $\times 10^{9} / \mathrm{L}$ & $61.27 \pm 28.98$ & $64.98 \pm 29.68$ & 0.424 \\
\hline Prothrombin time, s & $13.89 \pm 1.31$ & $13.49 \pm 1.26$ & 0.050 \\
\hline Serum creatinine, $\mu \mathrm{mol} / \mathrm{L}$ & $73.358 \pm 18.40$ & $76.70 \pm 26.96$ & 0.338 \\
\hline No. of endotherapy sessions & $3.54 \pm 1.63$ & $3.97 \pm 1.70$ & 0.102 \\
\hline \multicolumn{4}{|l|}{ Concurrent conditions } \\
\hline Portal venous thrombosis & & & 0.547 \\
\hline Absent & $82(77.4)$ & $52(81.3)$ & \\
\hline Present & $24(22.6)$ & $12(18.7)$ & \\
\hline Hepatocellular carcinoma & & & 0.844 \\
\hline Absent & 97 (91.5) & 58 (90.6) & \\
\hline Present & 9 (8.5) & $6(9.4)$ & \\
\hline Ascites & & & 0.549 \\
\hline Absent & $63(59.4)$ & $41(64.1)$ & \\
\hline Present & $43(40.6)$ & $23(35.9)$ & \\
\hline
\end{tabular}

Table 2. Continued

\begin{tabular}{lccc}
\hline \multicolumn{1}{c}{ Parameters } & $\begin{array}{c}\text { Poor } \\
\text { responders } \\
(\mathrm{n}=106)\end{array}$ & $\begin{array}{c}\text { Good } \\
\text { responders } \\
(\mathrm{n}=64)\end{array}$ & $\mathrm{p}$-value \\
\hline $\begin{array}{l}\text { EUS phenomenon } \\
\text { Para-gastric veins }\end{array}$ & $48(45.3)$ & $47(73.4)$ & \\
Absent & $58(54.7)$ & $17(26.6)$ & \\
Present & & & 0.000 \\
PGV classification & $48(45.3)$ & $47(73.4)$ & \\
None & $16(15.1)$ & $4(6.3)$ & \\
Type 1 & $42(39.6)$ & $13(20.3)$ & \\
Type 2 & & & 0.000 \\
Gastric perforating vein & $41(38.7)$ & $47(73.4)$ & \\
Absent & $65(61.3)$ & $17(26.6)$ & \\
Present & & & 0.000 \\
Esophageal perforating vein & & & \\
Absent & $37(34.9)$ & $40(62.5)$ & \\
Present & $69(65.1)$ & $24(37.5)$ & \\
\hline
\end{tabular}

Data are presented as number (\%) or mean \pm SD.

$\mathrm{HBV}$, hepatitis B virus; HCV, hepatitis C virus; $\mathrm{PBC}$, primary biliary cirrhosis; AIH, autoimmune hepatitis; GI, gastrointestinal; ALT, alanine transaminase; AST, aspartate transaminase; EUS, endoscopic ultrasound; PGV, para-gastric vein.

Table 3. Logistic Regression of Predictive Factor Analysis for Poor Response to Endoscopic Therapy

\begin{tabular}{llc}
\hline \multicolumn{1}{c}{ Variable } & \multicolumn{1}{c}{ OR $(95 \% \mathrm{CI})$} & $\mathrm{p}$-value \\
\hline Age & $0.947(0.911-0.986)$ & 0.007 \\
Hemoglobin & $0.984(0.968-0.999)$ & 0.035 \\
Prothrombin time & $1.144(0.862-1.520)$ & $\mathrm{NS}$ \\
Para-gastric vein & $5.374(1.013-28.475)$ & 0.048 \\
Gastric perforating vein & $2.908(1.174-7.201)$ & 0.021 \\
Esophageal perforating vein & $1.232(0.544-2.789)$ & $\mathrm{NS}$ \\
\hline
\end{tabular}

OR, odds ratio; $\mathrm{CI}$, confidence interval; NS, not significant.

of the follow-up endoscopy findings were closely correlated to the presence of para-gastric vein with a Pearson's correlation of 0.380 , p-value 0.002 .

\section{DISCUSSION}

Gastroesophageal variceal hemorrhage is a clinical adversity faced by clinicians that demands aggressive resuscitation and secondary prophylactic treatment after an index bleeding episode, necessitating multiple repeat endoscopic therapy sessions. ${ }^{1,31,32}$ The rate of gastroesophageal rebleed even after appropriate prophylactic therapy can exceed $40 \%$, with a high mortality rate. ${ }^{33}$ To date, no reliable prognostic indicator can accurately predict the occurrence of gastroesophageal variceal rebleed after appropriate prophylactic therapy, or better yet 
Table 4. Follow-up Endoscopy Findings for Poor Responders

\begin{tabular}{cc}
\hline \multicolumn{1}{c}{ Parameters } & No. (\%) \\
\hline Endoscopic findings & \\
Esophageal varices & $21(58.3)$ \\
None & $3(8.3)$ \\
Mild & $2(5.6)$ \\
Moderate & $10(27.8)$ \\
Severe & \\
Classification & $30(49.2)$ \\
None & $15(24.6)$ \\
EV & $4(6.6)$ \\
GOV type 1 & $8(13.1)$ \\
GOV type 2 & $4(6.5)$ \\
IGV type 1 & 0 \\
IGV type 2 & \\
Treatments received & \\
None & $32(52.5)$ \\
EBL & $12(19.7)$ \\
EIS & $1(1.6)$ \\
Cyanoacrylate & $8(13.1)$ \\
EBL+cyanoacrylate & $7(11.5)$ \\
EIS+cyanoacrylate & $1(1.6)$ \\
\hline
\end{tabular}

$\mathrm{EV}$, esophageal varices; GOV, gastroesophageal varices; IGV, isolated gastric varices; EBL, esophageal banding ligation; EIS, endoscopic injection sclerotherapy.

predict patient response to treatment. Carneiro et al. ${ }^{22}$ reported the diameter of paraesophageal varices before and after endoscopic band ligation as a predictive indicator for esophageal variceal recurrence. Irisawa et al. ${ }^{34}$ also reported severe type peri-esophageal collateral veins and large perforating veins signifies recurrence of esophageal varices. However, several EUS and angiographic studies suggest that extraluminal collaterals is responsible for a decrease in portal pressure after variceal obliteration, leading to a lower incidence of variceal rebleed. ${ }^{35-37}$ Unfortunately, most studies focused on the recurrence and rebleeding rates of esophageal varices after prophylactic treatment with EBL or EIS. To our knowledge, no available reports have investigated potential EUS predictors for variceal recurrence in patients with gastric varices or concurrent gastroesophageal varices.

The results of our studies revealed presence of para-gastric veins in $75(44.1 \%)$ subjects of the global population $(n=170)$. While 82 patients (48.2\%) presented with gastric perforating veins and 93 (54.7\%) patients with esophageal perforating veins. All patients with gastric varices were treated with cyanoacrylate injection via the sandwich technique (lauromacrogolcyanoacrylate-lauromacrogol). ${ }^{15}$ Concurrent esophageal varices were treated accordingly with EBL or EIS, determined by the operator.
Patients were divided into two groups based on their response to endoscopic therapy, which is determined by evident variceal rebleed prior to hospital admission or subsequent endoscopic findings. Statistical analysis between the two groups identified the presence of PGV, gastric perforating veins, and esophageal perforating veins as statically significant variables, with a $\mathrm{p}$ value $<0.001$, as well as age, hemoglobin $(\mathrm{g} / \mathrm{L})$, and prothrombin time (second). A binary logistic regression of the statistically significant variables revealed an OR of 5.374 (95\% CI, 1.013 to 28.475) for para-gastric vein, while that of gastric perforating vein was 2.908 (95\% CI, 1.174 to 7.201). Patients with paragastric vein are five times more likely to be poor responders to repeat endoscopic treatment compared to those without. Similarly, the presence of gastric perforating veins increases the risk of poor response by nearly 3 -fold.

Findings of the follow-up endoscopic examination of poor responders were also analyzed. Given the retrospective nature of the study, only 61 patients of the poor responder group had an available follow-up endoscopy examination. Variceal obliteration was observed in 32 patients (52.5\%), while remnant varices were present in 29 (47.5\%). The correlation between patient status was significantly correlated with the presence of paragastric vein, validating our previous findings.

Given comparable baseline characteristics, patient response to the endoscopic therapy may vary substantially. For some, variceal obliteration may be achieved in 2 to 3 endotherapy sessions, while other require far more. Our study attempted to identify poor responders to endoscopic therapy in order to promptly provide a better alternative treatment, avoiding unnecessary procedures. For instance, TIPS has shown to provide better treatment efficacy in severe portal hypertension or highrisk patients, which is often the culprit of treatment failure. ${ }^{17,38}$ Although, hepatic venous pressure gradient (HVPG) is the goldstandard for assessing portal pressure and assessing disease severity, and a decrease in HVPG of more than 10\% or HVPG $\leq 12$ $\mathrm{mm} \mathrm{Hg}$ is considered clinically relevant response to therapy. ${ }^{2}$ However, HVPG measurement is an invasive and relatively expensive procedure, which makes it an unrealistic method for disease assessment and surveillance. ${ }^{39}$

Our study concluded EUS phenomenon as a promising diagnostic modality for differentiating patient response to endoscopic therapy for gastroesophageal varices. The presence of para-gastric vein and gastric perforating vein substantially increases the risk of variceal recurrence. The detection of extraluminal phenomenon via endoscopic ultrasound is also a more feasible option compared to the costly and invasive HVPG measurement. EUS examination can also provide other valuable observations including the direction and speed of collateral blood flow, which require further investigation for its disease assessment or surveillance potential. Liver dynamic computed tomography (CT) may also provide valuable information of the collateral circulation. However, it may not be an ideal long-term 
surveillance modality given the exposure to radiation and use of contrast agents. Many gastroesophageal varices patients require more than one endoscopic therapy session and long-term follow up for the treatment of disease. Given comparable value, EUS may be a more appropriate surveillance option, while liver dynamic CT may be suitable for baseline evaluation in patients receiving initial endoscopic therapy or guiding treatment selection for poor-responders. For instance, detection of main portal vein thrombosis may be contraindicative of TIPS, while identification gastrorenal shunt may prompt a BRTO procedure.

There are several limitations to this study. HVPG was not available for the reference of disease severity. Changes in extraluminal collateral circulation after endoscopic treatment were not assessed. Not all patients had available endoscopic followup examination, which may hinder result validation. Majority of study subjects were classified as Child A and B, while the main etiology of cirrhosis is viral hepatitis (HBV). Application of study results on patients with advanced chronic liver disease (Child C) or different etiologies of portal hypertension require further evaluation.

EUS provides a pristine depiction of all extraluminal phenomenon with high clinical feasibility given adequate training of endoscopists. The recurrence of gastroesophageal varices is theorized to be directly correlated to disease severity or increase in portal pressure. Our results showed a remarkable correlation between para-gastric vein and poor response to endoscopic therapy for gastroesophageal varices, prompting a necessary change in course of treatment. Whereas patients without paragastric veins are urged to continue repeated endoscopic sessions to achieve complete obliteration with low risk of recurrence. EUS is a novel technology for investigating portal systemic collaterals in patients with gastroesophageal varices secondary to portal hypertension, with good correlation to routine endoscopic findings. ${ }^{19,40,41}$ The use of endoscopic ultrasound shows promising potential in stratifying patient response and risk to endoscopic therapy. However, the application for disease surveillance requires further investigation.

\section{CONFLICTS OF INTEREST}

No potential conflict of interest relevant to this article was reported.

\section{ACKNOWLEDGEMENTS}

The present study was supported by the Innovation Fund of Shanghai Scientific Committee (grant no. 15411950501) and the Foundation of Shanghai Municipal Commission of Health and Family Planning (grant no. 20154Y0065).

\section{REFERENCES}

1. Garcia-Tsao G, Sanyal AJ, Grace ND, Carey W; Practice Guidelines Committee of the American Association for the Study of Liver Diseases; Practice Parameters Committee of the American College of Gastroenterology. Prevention and management of gastroesophageal varices and variceal hemorrhage in cirrhosis. Hepatology 2007;46:922-938.

2. de Franchis R; Baveno VI Faculty. Expanding consensus in portal hypertension: report of the Baveno VI Consensus Workshop: stratifying risk and individualizing care for portal hypertension. J Hepatol 2015;63:743-752.

3. Garcia-Tsao G. Current management of the complications of cirrhosis and portal hypertension: variceal hemorrhage, ascites, and spontaneous bacterial peritonitis. Dig Dis 2016;34:382-386.

4. Hou MC, Lin HC, Lee FY, Chang FY, Lee SD. Recurrence of esophageal varices following endoscopic treatment and its impact on rebleeding: comparison of sclerotherapy and ligation. J Hepatol 2000;32:202-208.

5. Sarin SK, Lamba GS, Kumar M, Misra A, Murthy NS. Comparison of endoscopic ligation and propranolol for the primary prevention of variceal bleeding. N Engl J Med 1999;340:988-993.

6. de Franchis R; Baveno V Faculty. Revising consensus in portal hypertension: report of the Baveno $\mathrm{V}$ consensus workshop on methodology of diagnosis and therapy in portal hypertension. J Hepatol 2010;53:762-768.

7. Singh V, Singh R, Bhalla A, Sharma N. Cyanoacrylate therapy for the treatment of gastric varices: a new method. J Dig Dis 2016;17:392-398.

8. Levy MJ, Song WK. EUS-guided angiotherapy for gastric varices: coil, glue, and sticky issues. Gastrointest Endosc 2013;78:722-725.

9. Irani S, Kowdley K, Kozarek R. Gastric varices: an updated review of management. J Clin Gastroenterol 2011;45:133-148.

10. Bosch J, Garcia-Pagán JC. Prevention of variceal rebleeding. Lancet 2003;361:952-954.

11. D’Amico G, Pagliaro L, Bosch J. Pharmacological treatment of portal hypertension: an evidence-based approach. Semin Liver Dis 1999;19:475-505.

12. de Franchis R, Primignani M. Endoscopic treatments for portal hypertension. Semin Liver Dis 1999;19:439-455.

13. Sheibani S, Khemichian S, Kim JJ, et al. Randomized trial of 1 -week versus 2 -week intervals for endoscopic ligation in the treatment of patients with esophageal variceal bleeding. Hepatology 2016;64:549-555.

14. Sarin SK, Mishra SR. Endoscopic therapy for gastric varices. Clin Liver Dis 2010;14:263-279.

15. Zeng XQ, Ma LL, Tseng YJ, et al. Endoscopic cyanoacrylate injection with or without lauromacrogol for gastric varices: a randomized pilot study. J Gastroenterol Hepatol 2017;32:631-638.

16. Miyaaki H, Ichikawa T, Taura N, Miuma S, Isomoto H, Nakao K. Endoscopic management of esophagogastric varices in Japan. Ann Transl Med 2014;2:42. 
17. Monescillo A, Martínez-Lagares F, Ruiz-del-Arbol L, et al. Influence of portal hypertension and its early decompression by TIPS placement on the outcome of variceal bleeding. Hepatology 2004;40:793-801.

18. Garcia-Pagán JC, Di Pascoli M, Caca K, et al. Use of early-TIPS for high-risk variceal bleeding: results of a post-RCT surveillance study. J Hepatol 2013;58:45-50.

19. De Angelis C, Pellicano R, Carucci P, et al. Endoscopic ultrasonography in hepatology: focus on portal hypertension. Minerva Gastroenterol Dietol 2008;54:131-139.

20. Crisan D, Tantau M, Tantau A. Endoscopic management of bleeding gastric varices: an updated overview. Curr Gastroenterol Rep 2014;16:413.

21. Leung VK, Sung JJ, Ahuja AT, et al. Large paraesophageal varices on endosonography predict recurrence of esophageal varices and rebleeding. Gastroenterology 1997;112:1811-1816.

22. Carneiro FO, Retes FA, Matuguma SE, et al. Role of EUS evaluation after endoscopic eradication of esophageal varices with band ligation. Gastrointest Endosc 2016;84:400-407.

23. Suzuki T, Matsutani S, Umebara K, et al. EUS changes predictive for recurrence of esophageal varices in patients treated by combined endoscopic ligation and sclerotherapy. Gastrointest Endosc 2000;52:611-617.

24. Masalaite L, Valantinas J, Stanaitis J. The role of collateral veins detected by endosonography in predicting the recurrence of esophageal varices after endoscopic treatment: a systematic review. Hepatol Int 2014;8:339-351.

25. Sarin SK, Kumar A. Endoscopic treatment of gastric varices. Clin Liver Dis 2014;18:809-827.

26. Garcia-Tsao G, Lim JK; Members of Veterans Affairs Hepatitis C Resource Center Program. Management and treatment of patients with cirrhosis and portal hypertension: recommendations from the Department of Veterans Affairs Hepatitis C Resource Center Program and the National Hepatitis C Program. Am J Gastroenterol 2009;104:1802-1829.

27. Tajiri T, Yoshida H, Obara K, et al. General rules for recording endoscopic findings of esophagogastric varices (2nd edition). Dig Endosc 2010;22:1-9.

28. Arakawa M, Masuzaki T, Okuda K. Pathomorphology of esophageal and gastric varices. Semin Liver Dis 2002;22:73-82.
29. Sarin SK, Lahoti D, Saxena SP, Murthy NS, Makwana UK. Prevalence, classification and natural history of gastric varices: a longterm follow-up study in 568 portal hypertension patients. Hepatology 1992;16:1343-1349.

30. Sarin SK, Lahoti D. Management of gastric varices. Baillieres Clin Gastroenterol 1992;6:527-548.

31. Hwang JH, Shergill AK, Acosta RD, et al. The role of endoscopy in the management of variceal hemorrhage. Gastrointest Endosc 2014;80:221-227.

32. Chen YI, Ghali P. Prevention and management of gastroesophageal varices in cirrhosis. Int J Hepatol 2012;2012:750150.

33. D’Amico G, Luca A. Natural history: clinical-haemodynamic correlations. Prediction of the risk of bleeding. Baillieres Clin Gastroenterol 1997;11:243-256.

34. Irisawa A, Saito A, Obara K, et al. Endoscopic recurrence of esophageal varices is associated with the specific EUS abnormalities: severe periesophageal collateral veins and large perforating veins. Gastrointest Endosc 2001;53:77-84.

35. Yamamoto K, Onda M, Tajiri T. Correlation between angiographic features of esophageal varices and recurrence after endoscopic treatment. Hepatogastroenterology 1999;46:3136-3141.

36. Kakutani H, Hino S, Ikeda K, et al. Prediction of recurrence of esophageal varices-special reference to a role for endoscopic ultrasonography. Hepatol Res 2005;33:259-266.

37. Lo GH, Liang HL, Lai KH, et al. The impact of endoscopic variceal ligation on the pressure of the portal venous system. J Hepatol 1996;24:74-80

38. García-Pagán JC, Caca K, Bureau C, et al. Early use of TIPS in patients with cirrhosis and variceal bleeding. $\mathrm{N}$ Engl $\mathrm{J}$ Med 2010;362:2370-2379.

39. Vizzutti F, Arena U, Romanelli RG, et al. Liver stiffness measurement predicts severe portal hypertension in patients with HCVrelated cirrhosis. Hepatology 2007;45:1290-1297.

40. Lee YT, Chan FK, Ching JY, et al. Diagnosis of gastroesophageal varices and portal collateral venous abnormalities by endosonography in cirrhotic patients. Endoscopy 2002;34:391-398.

41. Irisawa A, Obara K, Sato Y, et al. EUS analysis of collateral veins inside and outside the esophageal wall in portal hypertension. Gastrointest Endosc 1999;50:374-380. 